\title{
Nurses matter: more evidence
}

\author{
Linda H Aiken, Douglas M Sloane
}

Center for Health Outcomes and Policy Research, University of Pennsylvania School of Nursing, Philadelphia, Pennsylvania, USA

\section{Correspondence to}

Dr Linda H Aiken, Center for Health Outcomes and Policy Research, University of Pennsylvania School of Nursing, Philadelphia, PA 19104, USA; laiken@nursing.upenn.edu

Accepted 30 August 2019 Published Online First

9 September 2019

\section{Sinked}

http://dx.doi.org/10.1136/ bmjqs-2018-009219

\section{Check for updates}

(c) Author(s) (or their employer(s)) 2020. No commercial re-use. See rights and permissions. Published by BMJ.

To cite: Aiken $L H$, Sloane DM. BMJ Qual Saf 2020;29:1-3.
Empirical evidence from many published studies indicates that better hospital professional registered nurse (RN) staffing is associated with better patient outcomes, including lower mortality and failure to rescue, shorter lengths of stay, fewer readmissions, fewer complications, higher patient satisfaction and more favourable reports from patients and nurses alike related to quality of care and patient safety. ${ }^{1-10}$ There are nonetheless lingering questions and concerns about these studies and the evidence they provide. In this issue of BMJ Quality \& Safety, Needleman et $a l^{11}$ allude to some potentially important ones in their introduction to their paper, including making causal inferences from cross-sectional studies, the absence of evidence on whether there is an optimal level of staffing or some level of minimally acceptable staffing below which nurses are unable to deliver high-quality and safe care, the absence of measures of work environment and its impact in many studies and whether the greater or lesser presence of nursing support staff affects patient outcomes independent of, or that acts in conjunction with, the level of RN staffing.

With this study by Needleman and colleagues, BMJ Quality \& Safety has now published three recent papers on the outcomes of hospital nurse staffing ${ }^{11-13}$ that are responsive in different ways to some of the lingering questions about the outcomes of nurse staffing and their implications for policies and managerial decisions about investments in nursing personnel to achieve the greatest value. The first paper in the series by RN4CAST researchers ${ }^{12}$ used unique cross-sectional data to study the outcomes of variation in nurse staffing in 243 hospitals in six European countries. The outcomes included were mortality among patients who had undergone common surgical procedures, patients' ratings of their hospitals, nurses' assessments of quality of care and adverse care outcomes, and nurse burnout and job dissatisfaction. The study included comprehensive measures of the clinical work environment and the percentage of nurses in each hospital with bachelor's qualifications, omissions in much previous research on the outcomes of nurse staffing noted by Needleman and colleagues. The study concluded that every 10 -point increase in the percentage of RNs among all hospital nursing personnel was associated with $11 \%$ lower odds of mortality and 10\% lower odds of low patient ratings of their hospitals after controlling for total nursing personnel staffing, quality of the work environment, per cent of bachelor's prepared nurses and other hospital features that might explain the association between the percentage of RNs on outcomes including availability of technology, teaching status and bed size. A limitation noted by the researchers was the study's cross-sectional design that limited causal inferences.

The second and third papers ${ }^{11} 13$ used research designs that were different from the RN4CAST paper but similar to one another, examining the outcomes of nurse staffing variation at the unit level using a retrospective longitudinal design and measuring daily or shift variation in $\mathrm{RN}$ staffing for patients in one hospital in England ${ }^{13}$ and a three-hospital campus in the USA. ${ }^{11}$ Griffiths et al ${ }^{13}$ found that the hazard of death was increased by $3 \%$ for every day an adult medical or surgical patient experienced RN staffing below the ward mean. Needleman and colleagues had a similar finding that the hazard of death was significantly increased when RN staffing was low, defined as $75 \%$ or lower than the ward median.

All three papers confirm-at least with respect to mortality-that low RN staffing increases the risk for poor outcomes for patients. What is especially important about the confirmation provided by the Needleman et $a l^{4} 11$ and Griffiths $e t a l^{13}$ papers is that they show longitudinal associations between $\mathrm{RN}$ staffing and patient outcomes at the 
patient level, within hospitals, which suggests that the cross-sectional associations found in studies that use hospital-level RN staffing data and compare outcomes across hospitals, such as the RN4CAST study, are more likely to be causal than artefactual and reflect differences in patient exposures to different staffing levels as well. We provide additional evidence of this in our own recent work, ${ }^{14}$ in which we use panel data from 737 US hospitals in 2006 and 2016 and investigate whether changes in nursing resources over time within hospitals are related to changes in quality of care and patient safety. We find that improvements within hospitals in RN staffing, as well as improvements in work environments and educational composition of RNs, coincide with improvements in quality of care and patient safety and that longitudinal panel results closely approximate cross-sectional results.

Where the Needleman et al paper differs from both Griffiths $^{13}$ and the RN4CAST study ${ }^{12}$ is in its finding that low assistive nurse staffing is associated with higher patient mortality, and their conclusion that decision makers should ensure the adequacy of both assistive and RN staffing. Griffiths et al, ${ }^{13}$ with a similar design to the Needleman et al study, found that low as well as high assistive nurse staffing was associated with higher risk of patient mortality. The authors thus cautioned policy makers not to develop a single targeted staffing ratio that includes both $\mathrm{RN}$ and assistive staff hours because assistive staff are not substitutes for RNs. The findings of the RN4CAST paper on the outcomes of nursing skill mix are closer to those of Griffiths et al than to Needleman et al, showing, for example, that substituting one nursing assistant for an $\mathrm{RN}$ for every 25 patients is associated with a $21 \%$ increase in the odds of dying.

The Needleman et al finding on assistive nursing staff is also counter to two of Needleman's previously published papers, one that found no evidence of an association between number of licenced practical nurse (LPN)-hours or aide-hours per day, or a higher proportion of aide-hours, on any of the many patient outcomes they studied, except for length of stay ${ }^{1}$; Needleman's other study estimated that holding constant the total number of hours of licenced nurse care (RNs+LPNs) and replacing LPN hours with RN hours would result in lower mortality and net savings. ${ }^{15}$ Stone, a coauthor of the Needleman et al paper in this issue, has also published a previous paper showing that higher LPN staffing levels were associated with higher rates of mortality and sepsis in trauma patients. ${ }^{16}$ Sir Brian Jarman ${ }^{17} 15$ years ago published a large study of determinants of hospital mortality in National Health Service (NHS) hospitals in England that found that the greater the proportion of auxiliary care staff, the higher the mortality. A recent study of NHS hospitals confirmed that more healthcare support workers were associated with higher mortality. ${ }^{18} \mathrm{~A}$ large multihospital study in the USA documented that more assistive nursing personnel were associated with higher mortality among medical patients hospitalised with acute myocardial infarction. ${ }^{19}$ This is not meant to be an exhaustive list of studies with findings counter to those of Needleman et al but illustrates that there is a substantial evidence base with opposing findings. Their paper does not provide a compelling explanation for why their particular study would have findings different from so many others and why it would be appropriate to generalise from one small study to other hospitals.

The Needleman et al finding that low nursing support staffing is associated with higher mortality is notable for two reasons. First, as mentioned, there are a number of other studies finding the opposite, and many of them are large multihospital studies. They include studies of different patient populations and of hospitals in different countries. Is there enough evidence in their one paper to suggest that the Needleman et al findings could be generalised beyond the hospitals studied? The second reason the assistive nurse staffing finding is notable is its possible misuse by decision makers seeking to save money by employing less expensive workers. Granted the authors say that their findings should not be interpreted to mean that nursing aides can safely substitute for RNs. However, an early news article on the study had the following opening sentence: 'Low nursing assistant staffing is just as much a risk to the lives of patients than inadequate registered nurse levels, U.S. researchers have found' ${ }^{20}$

We think a more productive area for research than debating the contributions of nurse assistive staff to reducing mortality risks in hospitals is to follow in the footsteps of Florence Nightingale-one of the first healthcare outcomes researchers. Nightingale rigorously researched the impact of the introduction of trained nurses on mortality in military hospitals. Once having established an association between trained nurses and reductions in patient deaths, she spent much of her life advocating for these findings to be widely translated into practice to improve the quality and safety of hospital care. The International Year of the Nurse and Midwife in 2020 in recognition of the 200th anniversary of Florence Nightingale's birth is a fitting time to take action based on the preponderance of evidence to date that good professional nurse staffing results in safer and higher quality hospital inpatient care. More jurisdictions every year are developing and implementing interventions to improve hospital RN staffing, including Wales; Scotland; Ireland; Queensland, Australia; South Korea and multiple US states among others. Learning from these interventions and those of the future through independent prospective studies offers the greatest payoff for research and policy by establishing whether there is causal evidence that improved nurse staffing results in better patient outcomes. 
Funding The authors have not declared a specific grant for this research from any funding agency in the public, commercial or not-for-profit sectors.

Competing interests None declared.

Patient consent for publication Not required.

Provenance and peer review Commissioned; internally peer reviewed.

\section{REFERENCES}

1 Needleman J, Buerhaus P, Mattke S, et al. Nurse-staffing levels and the quality of care in hospitals. N Engl J Med Overseas Ed 2002;346:1715-22.

2 Aiken LH, Clarke SP, Sloane DM, et al. Hospital nurse staffing and patient mortality, nurse burnout, and job dissatisfaction. JAMA 2002;288:1987-93.

3 Aiken LH, Cimiotti JP, Sloane DM, et al. Effects of nurse staffing and nurse education on patient deaths in hospitals with different nurse work environments. Med Care 2011;49:1047-53.

4 Needleman J, Buerhaus P, Pankratz VS, et al. Nurse staffing and inpatient hospital mortality. N Engl J Med 2011;364:1037-45.

5 Blegen MA, Goode CJ, Spetz J, et al. Nurse staffing effects on patient outcomes: safety-net and non-safety-net hospitals. Med Care 2011;49:406-14.

6 Aiken LH, Sloane DM, Bruyneel L, et al. Nurse staffing and education and hospital mortality in nine European countries: a retrospective observational study. Lancet 2014;383:1824-30.

7 Cimiotti JP, Aiken LH, Sloane DM, et al. Nurse staffing, burnout, and health care-associated infection. Am J Infect Control 2012;40:486-90.

8 Aiken LH, Sermeus W, Van den Heede K, et al. Patient safety, satisfaction, and quality of hospital care: cross sectional surveys of nurses and patients in 12 countries in Europe and the United States. BMJ 2012;344:e1717.

9 Shekelle PG. Nurse-patient ratios as a patient safety strategy: a systematic review. Ann Int Med 2013;158:404-9.
10 Griffiths P, Ball J, Drennan J, et al. Nurse staffing and patient outcomes: strengths and limitations of the evidence to inform policy and practice. Intl J Nurs Stud 2016;63:213-25.

11 Needleman J, Liu J, Shang J, et al. The association of registered nurse and nursing support staffing with inpatient hospital mortality. BMJ Qual Saf 2020;29:10-18.

12 Aiken LH, Sloane D, Griffiths P, et al. Nursing skill mix in European hospitals: cross-sectional study of the association with mortality, patient ratings, and quality of care. BMJ Qual Saf 2017;26:559-68.

13 Griffiths P, Maruotti A, Recio Saucedo A, et al. Nurse staffing, nursing assistants and hospital mortality: retrospective longitudinal cohort study. BMJ Qual Saf 2019;28:609-17.

14 Sloane DM, Smith HL, McHugh MD, et al. Effect of changes in hospital nursing resources on improvements in patient safety and quality of care. Med Care 2018;56:1001-8.

15 Needleman J, Buerhaus PI, Stewart M, et al. Nurse staffing in hospitals: is there a business case for quality? Health Aff 2006;25:204-11.

16 Glance LG, Dick AW, Osler TM, et al. The association between nurse staffing and hospital outcomes in injured patients. BMC Health Serv Res 2012;12:247.

17 Jarman B, Gault S, Alves B, et al. Explaining differences in English Hospital death rates using routinely collected data. BMJ 1999;318:1515-20.

18 Griffiths P, Ball J, Murrells T, et al. Registered nurse, healthcare support worker, medical staffing levels and mortality in English Hospital trusts: a cross-sectional study. BMJ Open 2016;6:e008751.

19 Person SD, Allison JJ, Kiefe CI, et al. Nurse staffing and mortality for Medicare patients with acute myocardial infarction. Med Care 2004;42:4-12.

20 Mitchell G. Combined nurse and assistant staff shortages 'increase patient death risk'. Nursing Times. Available: http:// www.nursingtimes.net/news/workforce/combined-nurseassistant-staff-shortages-increase-patient-death-risk-22-082019/ [Accessed 24 Aug 2019]. 